\title{
CPA Firms of Human Resource Management Research A Case Study of SCPA
}

\author{
Yingying $\mathrm{Li}^{1, *}$ \& Yanni Yao ${ }^{1}$ \\ ${ }^{1}$ Management Faculties of Graduate Students, Shanghai University of Engineering Science, Shanghai, China \\ *Corresponding author: Management Faculties of Graduate Students, Shanghai University of Engineering Science, \\ Longteng road No.333, Songjiang district, Shanghai, China. E-mail: 550422762@qq.com
}

Received: March 29, 2014

Accepted: April 23, $2014 \quad$ Online Published: May 30, 2014

doi:10.5430/mos.v1n2p78

URL: http://dx.doi.org/10.5430/mos.v1n2p78

\begin{abstract}
With the development and improvement of Chinese market economy, CPA firms play a more and more important role. However, many problems exit in the course of CPA firms' growth. Among those problems, un-standard human resource management is a key component of constraints to the development of our CPA business development. Human resource management of CPA firms is in disorder. All those are obstacles to the continuous development. Thus, it will be the priority condition to improve current human resource management situation, advance human resource allocation, and fully encourage potential capability of employees. Based on the above consideration, on an accounting firm in Shanghai and analyzes the problems existing in the human resources management, from the perspective of human resource management to discuss how to make the firm get rid of the disadvantages of existing, keep and continuously improve their competitiveness.
\end{abstract}

Keywords: certified public accountants; human resource; human resource management

\section{The Status Quo of Human Resource Management about SCPA}

Since establishment, SCPA has firmly adhered to the principle of "Sincerity first, Service first and Efficiency first" policy. With the national reform going continuously further, we will made all efforts to explore and develop continuously to improve our professional service, and provide our professional service to our clients, both old and new, with a new enthusiastic outlook.

\section{The Concept of SCPA and Its Development History}

Shanghai Certified Public Accountants (SCPA) was established in January 1981. Catering to the opening up of China, it is the first accounting firm set up in china, as authorized by the Ministry of Finance of the P.R.C. It is one of the few accounting firms that are qualified and approved by Ministry of Finance and China Securities regulatory Administrative Committee to conduct the auditing of the listed companies. At the end of the 1998, SCPA was transformed into a limited liability accounting firm invested and managed by Chinese qualified accountants as required by the Ministry of Finance and China Securities regulatory Administrative Committee.

Over the 20 years since its establishment, SCPA has won profound trust form clients deeply for its emphasis on the quality of operation and service, its upholding of profession morality and ceaseless expansion of service scope. SCPA keeps favorable business cooperation relations with renowned international accounting firms. At present, SCPA employs about 300 staff members, including over 100 certified public accountants. All the certified accountants have college degrees at the lowest and attend national training and further education regularly. Some certified accountants have been sent abroad or to Hong Kong for training and practice. All of our employees have strong enterprise and rich practical experience. So SCPA is an accounting firm with a considerable scale, the longest history in China and a favorable credit standing. 


\section{The Human Resources Management Current Situation Analysis of SCPA}

Although the club's business better, more stable business, the income of employees are more lucrative. However, the club's personnel structure described above but there is a crisis:

Firstly, looking at the age and length of service, a large number of employees are under 30 years old. Because our accounting policies in recent years have a huge change, accounting standards, corporate accounting system constantly getting close to the international accounting system. Objectively cause customers to believe that the rich work experience personnel who can solve the problem and provide audit services relatively ages 30 to 40 years old stage. Because these people are young, absorb and master the latest domestic accounting, tax changes in policies and regulations. These people have rich sense of responsibility, and customer things as their own things to do.

Secondly, from the recruiting of SCPA, the people mostly are accountants, auditors and evaluators. The minority rest of people are engaged in managing and tax consulting. Because the development of SCPA focus on the traditional auditing service, the old employees have the same thought all the time, and they are lack of divergent thinking (Fiona Robson, 2010). What they can offer are only the service of auditing, and they are mostly short of confidence and knowledge to manage the field. It is stopping the development of pluralistic economy.

Thirdly, staff liquidity is bigger and there is no career planning for employees. It contributed to the employee's absent. For a long time, CPA firms managing his staff as labors but not families. There is no regular professional training (CPA just have to attend the Shanghai Institute of CPAs and other industry organizations in charge of training), and there is no assessment of employees, not said remuneration incentives and performance evaluation. The results of this kind of situation are employees' motivation and initiative decline, grab power blame-shifting and poor teamwork.

All these negative factors on human resource structure will be located on both the market economy and diversified economic development inconsistent.

\section{Analyze the Reasons of SCPA’s Human Resource Management Issues}

\subsection{Leading Factors}

SCPA as a country's first accounting firm, experienced from the state government-run holdings to the restructuring. However, SCPA now is a so-called private enterprise, and the manager's thinking hair remains on state-owned enterprise management mode.

From the administrative point to view, there are chief accountant, deputy chief accountant, department managers, department assistant manager, project manager, presiding CPA, assistant certified public accountants, and other professionals and interns ten administrative level in SCPA (Dongying Chen, 2010). Organizational structure "pyramid" type of organization theory under traditional management mechanisms causing unreasonable, resulting in bloated, excessive levels, and poor coordination, often form obstacles to the effective delivery and management of information. So that information cannot be shared, teamwork spirit cannot be effectively playing, and employees cannot participate in collective decision-making, which is not conducive to the formation and manifestation of democracy, equality and corporate culture.

\subsection{Institutional Factors}

The imperfection of training, evaluation and incentives systems: Staff training is a human resource management firm's an important content, including both training for new staff and managers at all levels of the firm's. Over the years, SCPA effective training, evaluation system and incentive mechanism has not been formed.

Lack of objective performance evaluation criteria: Performance evaluation of the standards process is not very scientific, impartial and objective from the current SCPA bonus allocation. And the content of performance evaluation, evaluation criteria, evaluation methods have not done to the public, often in the "black box" operation (Ting Cheng, 2011). It makes staff doubts and discontent, and there is no objective quantitative criterion. Performance evaluation criteria resulting ambiguity between staff and employees, conflicts between workers and firms, motivate employees to work without them, reducing the use of performance of human resources. Some employees even because of that compensation is unfair and unreasonable and stormed off, resulting in the enterprise is difficult to retain talent.

\subsection{Managers Perform Factors}

For a long time, the firm's managers have been in a professional business-oriented, the so called "the trial and 
officials." Long with numbers, such audited financial statements of the "heavy micro, light macro" habits of the "short-sighted" of management, execution greatly reduced. Thus resulting in a series of management problems, specific performance:

Managers lack unremittingly tenacity, the performance of the implementation of the policy is not consistent, the beginning of the work tends to be organized, planned, but when the time and work were going, enthusiasm began to gradually cooling. The firms will be far less checks and forget to urge (John A. Brierley, David R. Gwilliam, 2003).

The CPA firms' internal organizations are unscientific, and their management structures' allocation is irrational. From the perspective of management and control functions of institutions set up modern enterprise status, now firm management system functions to set too many functions to configure unscientific. There is a large number of overlapping functions and overlap.

Policy arbitrariness and uncertainty tripped execution legs: The introduction of policies and systems administrators, the repeated demonstration and careful scrutiny, resulting in frequent flip-flop policies and institutions, so that executives don't know what to do. Policy and the system itself is unreasonable, the lack of guidance, relevance, feasibility is not conducive to the implementation or too cumbersome.

The job performance evaluates roughly, and it is difficult to play incentives to promote the role.

The promotion of leadership positions is unfair, unjust and middle managers of the general lack of progress in the pursuit of power and passion: job promotion has always been the most important means of human motivation, however, the firm's current practice of job promotion system so that incentives effect is difficult to play.

\subsection{The Construction of Enterprise Culture's Factors}

Corporate culture is the ideals and beliefs of employees engaged in the commodity business activities which have in common, values and codes of conduct. It is an ideology explicit in corporate style, and it reflects in the mind of the staff to the values at the core.

We can say that SCPA is now in a "non-cultural phenomenon" of the state, even though the system has a very firm and strict rules and regulations. The provisions of these regulations and the staff cannot do what must be done, but there is no clear cultural ideas and values advocated, neglect of education and training of employees. The reason I think the key is the quality of the management and leadership of the firm itself, the lack of understanding of corporate culture. Lagging firm's corporate culture has become an obstacle to business development firm, bottlenecks.

\section{To Perfect SCPA's Human Resource Management Strategies and Thoughts}

The above will be located on human resources management, and there are many problems which are serious impediment to the development of the firm. SCPA wants to get rid of all the difficulties faced by the firm to maintain the strength and growing competition in the market, in order to meet the challenges ahead (Hongqin Zhang, 2011). We must strengthen the capable of human resources management, give full play to their potential, and stimulate the vitality of the firm. SCPA choose their own living environment and the specific historical conditions of human resources management, answers and solve the challenges of the environment and conditions proposed. Therefore, SCPA must always study the new changes in the external environment and, if necessary, to the company's human resources management system to be adjusted accordingly.

\subsection{Establish a "People-Oriented" Strategic Thinking}

Currently, SCPA's managers lacking adequate training of personnel development, rational use of personnel and the concept of effective incentive management personnel, which greatly hindered the development of the firm. Person is the core and the power in firms. They are invincible firms in the increasingly fierce market competition, and it is an important guarantee. Due regard will be located on the money, business income, the objective environment cannot and some large international accounting firms and accounting firms to compete, which often is SCPA that just by virtue of their ability to insurmountable obstacles, SCPA can grasp and control its human resources. Therefore, SCPA must establish a "people-oriented" strategic thinking, attention to the development and utilization of human resources.

\subsection{Develop Human Resource Management Strategy}

Human resources management strategy is a part of the firm's business strategy. It is not isolated, mechanical, but it is dissolved into the firm's overall strategy. Thus, you cannot put human resource management activities with other 
management activities firms separated, and you should make the two coincide. I think CPA firm at different stages of development should take a different human resources management strategy, aligning them with the firm's competitive strategy accordingly.

The start-up phase - -family management strategies: Firm as an economic organization, it depends on the establishment of basic social mechanisms such as property rights, contracts, and a series of laws, etc. It also depends on the degree of social awareness and community members an ethical mutual trust between each other. In the initial stage of the firm, the firm is small, slow sales growth, lower service product market share, profits will barely even a loss. This time, the operator can take the families' human resource management strategy, through hiring personnel familiar with the use of social relationships to establish a trust relationship necessary for a modern market economy, reduce monitoring costs.

Development Stages - -a tendency recruitment strategy: Firm in the development stage, the rapid increase customer awareness, sales surge, profits also showed growth acceleration, the firm is expanding. At this point, the firm faces the challenge of technical specialization and professional management, the original members of the firm have been difficult to guarantee the sustainable development of the firm, and personnel structure and management strategy grew out of families' shortcomings become firm developing human resources management of the " bottleneck". CPA firms attract talent to break through human society "bottleneck" has become a top priority. Human resource management firm focused on attracting talent, recruitment and selection of top talent, and gradually formed the seeds of the corporate culture. The strategies of human resources management office from the original family management strategies turn to the recruitment strategy.

Mature stage -- training and development and incentives strategies: Firms in the mature stage, market position is relatively stable, with less risk, profit growth slow or no growth, firm personnel has reached a certain size, does not require a large scale to attract talent, and a range of needs to be adjusted. Stability talent is firm at this stage focus. ${ }^{[7]}$ At this point, how to make good use of their talent, and maximize the value of existing staff to become a key human resource management firm. Therefore, firms mature stage, one of the key human resource management is carried out by existing staff training and development, improve the quality of existing staff, and create incremental human capital, so as to provide continuous innovation potential, so with the pace of development of their respective firms, ready to meet new challenges.

Re- start-up stage -- the tendency of corporate culture strategy: Firm in its development to a certain extent, the passion of its start-up period is disappearing. Some people are leaving the firm and find others which can get more money. To get out of this state, firms should conduct a comprehensive internal reform and strengthen efforts to culture. In the consolidation phase, the firm's first task is to complete the change of senior managers. And this Meanwhile, firms in the growth stage of the recruitment of management personnel who have the knowledge and modern management level, after several years of running and exercise in the firm, has grown up, so this stage is the firm for the most senior management personnel change good times. Alternating smooth completion of senior managers is whether the relationship between the firm plight faced by the glory of the key. Another task is to rectify the cultural stage of construction enterprises, entrepreneurial firms to successfully enter another phase of the foundation.

I think the current situation on the club should be in the mature stage and start-up phase, it should focus on building training should be developed, incentives and corporate culture.

\subsection{Building Human Resource Management System}

CPA's Human resource management should be firm service development and reform, so firms' all elements of human resources management in the firm first established jointly identified by management, in line with interests of all parties inside and outside the firm and get Affairs firm foundation and vision of the strategic objectives agreed on by the members, while strengthening the intrinsic link recruitment hiring, performance evaluation, compensation and human resources development, allocation of human resources management between various elements to achieve the integration of various elements of the system in order to achieve systematic management of human resources (Huiting Chen, 2012). The impact of corporate culture on human resource management system is shown in Figure 1 


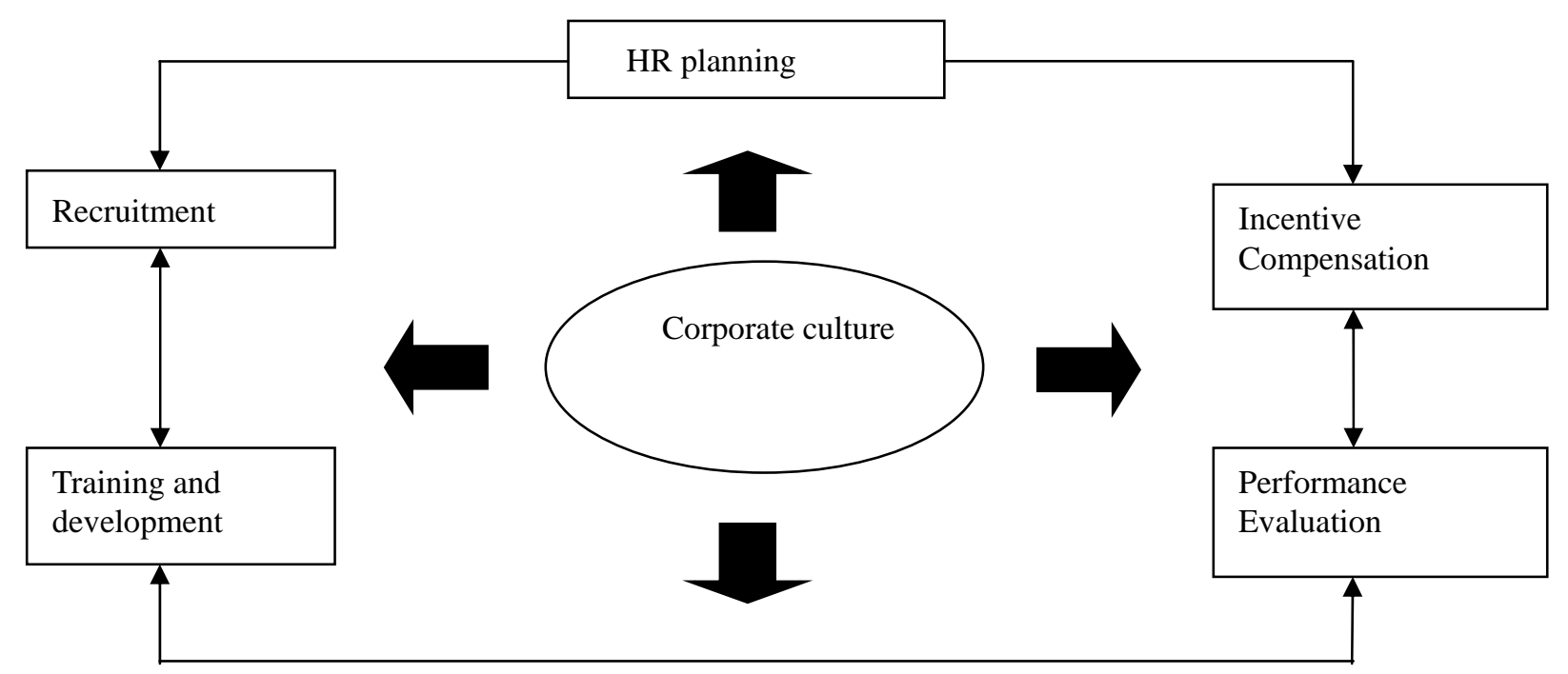

Figure 1. Corporate Culture Effect Human Resources Management System

Just as shown in Figure 3.3, the several elements are not isolated, but interrelated, mutual restraint. Corporate culture is the core of all elements, which determines the recruitment hiring a certain extent. Corporate culture also determines the training development, different corporate culture training and development for the degree of attention and intensity varies. Corporate culture also affect the performance evaluation of the performance evaluation of employees contains the degree of adaptation to the firm's employees. So the actual corporate culture affects employee job performance, and it also affects how others evaluate this performance. Influence of corporate culture on compensation incentives should not be overlooked. A firm focused on internal or external reward incentive compensation incentives, often depends on the culture of the firm. Human resources plan for job opportunities play a decisive role, which determines the source of job opportunities, methods and quantity. Between job opportunities and training development, training and development and performance evaluation, all affect each other between performance evaluation and reward incentive, mutual restraint. Incentive compensation or performance evaluation criteria on which to perform, and the results will reward incentives and performance evaluation of employees have some impact, but it also affects the development and implementation of human resource programs to some extent (Peter - Senge, 1994).

\subsection{To Improve the Overall Quality of Firm Personnel}

Improve the quality of leadership: The key to success lies in the leader's own qualities in CPA's firms. If the leaders don't have own foresight, vision, and do not understand the use of personnel, then this firm is difficult to sustainable development. Therefore, improving the firm's own quality leadership is a prerequisite for human resource management firm. A good leader should have the right philosophy and a good image, in Figure 2 reflects. 
Internal public $\quad$ Leader image $\quad$ Leader image $\quad$ External public

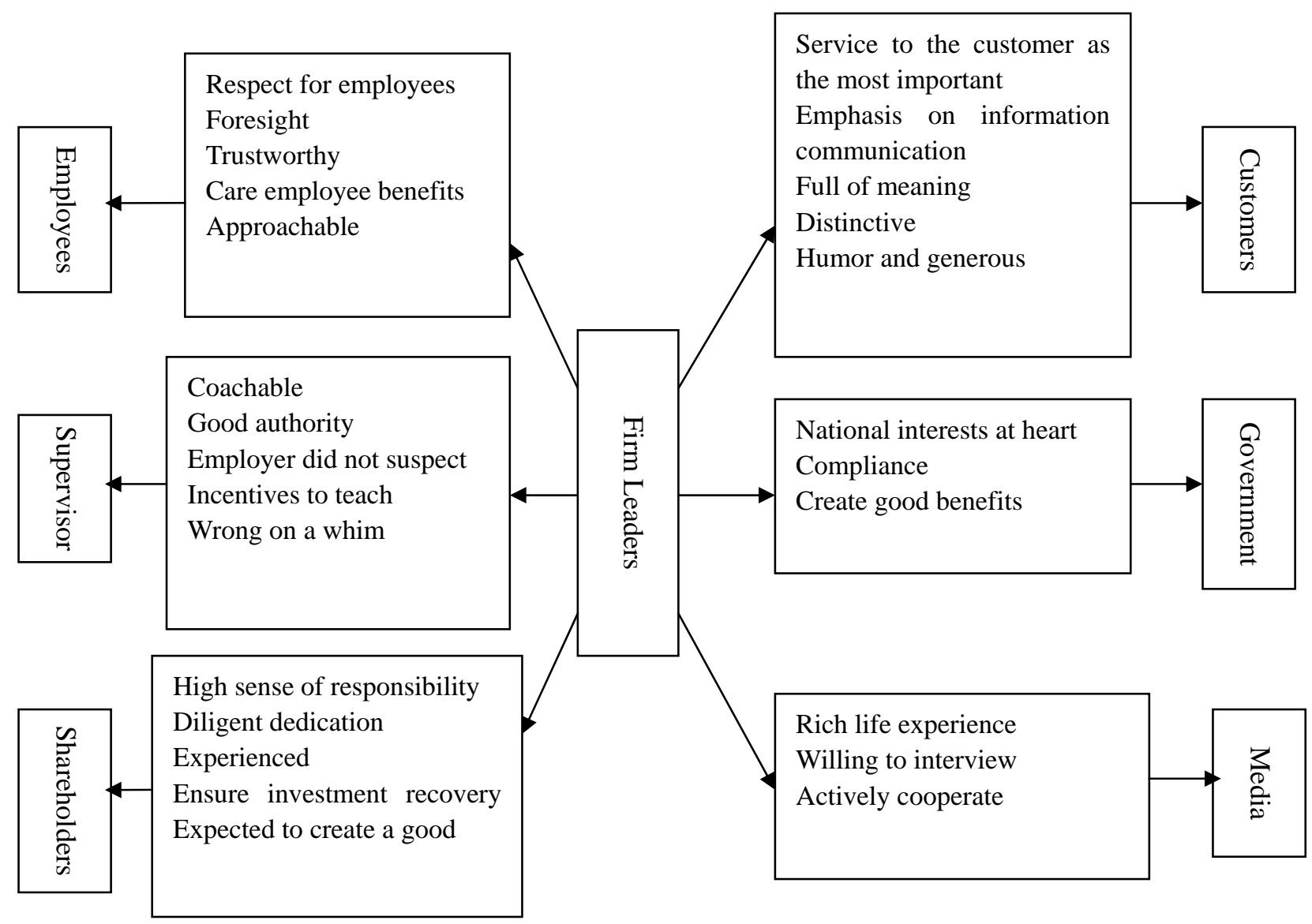

Figure 2. Excellent Firm Leaders Should Have a Good Image of the Schematic

Improve the quality of staff training: We can improve the quality of staff from two ways. On the one hand is to improve the ideological and moral quality of staff. Another way is to improve the knowledge, skills, quality of staff.

First, training the staffs' values, and expanding the activities of the firm around the core values. Second, training the staffs' professional skills and management theories is very important. Staff training and training in intellectual capital is the most important part. It can greatly improve the overall quality of the person's ability to create long-term benefits which brings more than physical capital investment will give firms (Sinikka Vanhala, Eleni Stavrou, 2013). Therefore, firms should strive to use intellectual capital investment, with the abundant human resources into alternative advantages of material resources, natural resources and technology.

\subsection{To Create a Multi-Dimensional Cross-Personnel Incentive System}

Incentives simplification is a major flaw of human resource management firm. In order to effectively motivate staff morale, to maximize the potential of firm employees, the firm should enrich the existing incentives to achieve multidimensional incentive system development. According to motivational theory, factors of personal effort varied. Integration of various motivational factors indicated in Figure 3. 


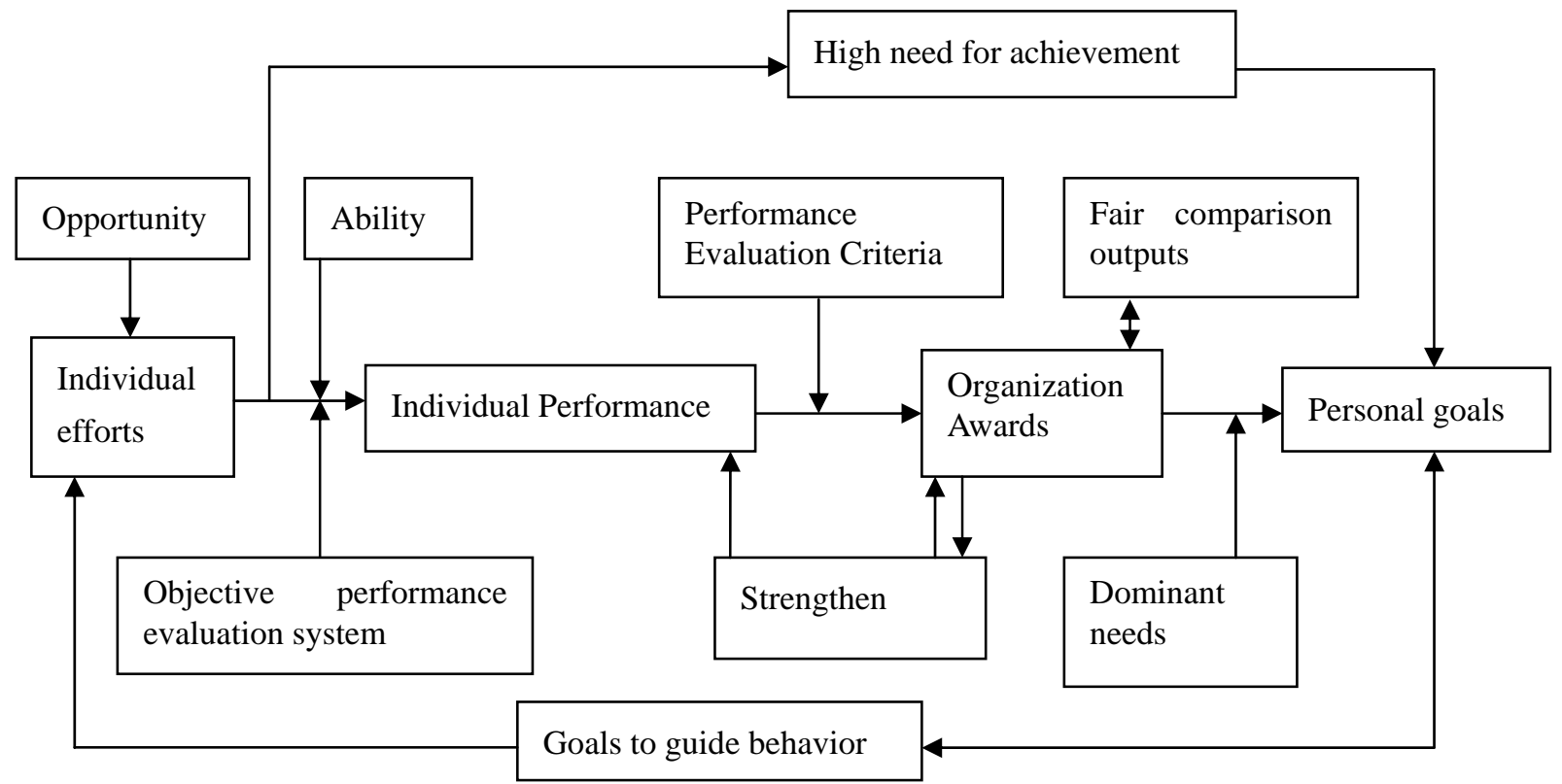

Figure 3. Schematic of Various Incentives for Integration

Individual performance, personal goals, responsibility, opportunity, fairness, achievement, etc., may promote or hinder individual effort (Xiuping Hao, 2013). Therefore, firms should be under different circumstances, at different time periods, taking local conditions in different incentives to different people.

\subsection{Create Excellent Corporate Culture}

Any business has its own culture, but these did not necessarily have a culture conducive to continuously improve business performance. A good business is to create an enabling business staff would agree with the core values and mission. An employee can contribute to uplifting psychological environment, to ensure a continuous improvement of business performance. One can actively promote organizational change and development of the corporate culture. To achieve such a state, the firm must first establish a "common vision" for all employees. It is the firm intention or scenes in which people are held in common, and is the one in the minds of people inspired by the power of it create a crowd is one of the feel and the full range of activities throughout the firm, leaving integrate different activities.

SCPA will be located on the building of enterprise culture in the process, and we need to fully understand the culture of a firm which requires a long "to become" process, rather than a few carefully planned what can be resolved at the same time. The corporate culture is by no means purely natural selection process, and it is a need for more "human" actively involved in the cultivation process.

\section{Conclusions}

In summary, the CPA firm's human resource management system is a long-term project. Only to establish a "people-oriented" thinking, with strategic vision to develop human resource management strategies, and with the establishment of scientific recruitment, performance evaluation, talent development and compensation incentive systems, as well as create excellent corporate culture, we can make firm has a lingering charm, in order to achieve firm demand for talent and talent fit their needs. Finally CPA firms can be married into the firm needed to fit the requirements of talents, and make people do their job, their talent is firm dedicated to ensure firms in the fierce market competition to maintain and constantly enhance their competitive advantage. The SCPA's human resources management should always implement the "people-oriented" thinking, need to do the following things:

(1) Full implementation of the firm's training system will be able to unite all the training into employee engagement, which increasing employee loyalty catalyst for firms. The last it will improve people's overall quality and the ability to create, and to reduce the risk of firm's practice;

(2) Establish the multi-dimensional development of incentive systems. Through the establishment of economic and non-economic reward incentive system, the long-term development of its own staff development and firm, closely linked to the economic benefits, and employees of both firms to increase trust and confidence, stimulate 
potential employees to develop and development firm and common progress;

(3) Learning organizational, professional ethics education's strengthen, the overall quality of the staff and leadership's improvement, to help employees improve their skills, ability to work. And this play is the responsibility of the firm where, as a leader firm also must have some basic qualities.

(4) Establish a "united, progressive, efficient service" corporate culture which is the purpose of the firm, so that CPA firms truly be impartiality and integrity and cultural harmony. It creates a good atmosphere for future development.

\section{References}

Dongying Chen. (2010). CPAs Human Resource Issues and Counter Measures. Goods and Quality Forefront of Observation, 15(1), 92-98.

Fiona Robson. (2010). Research Methods in Human Resource Management (2nd ed.). Personnel Review, 39(1), 155-157.

John A. Brierley \& David R. Gwilliam. (2003). Human resource management issues in audit firms: a research agenda. Managerial Auditing Journal, 18(5), 431-438. http://dx.doi.org/10.1108/02686900310476891

Hongqin Zhang. (2011). Small Firms' Environmental Analysis. Business Accounting, 17(4), 67-71.

Huiting Chen. (2012). CPA Knowledge Worker Management Mechanism. Zhejiang Industry and Commerce University, 20(3), 121-127.

Peter Senge. (1994). Fifth Discipline a Learning Organization the Art and Practice. Shanghai Joint Publishing, 1994 edition.

Sinikka Vanhala \& Eleni Stavrou. (2013). Human resource management practices and the HRM-performance link in public and private sector organizations in three Western societal clusters. Baltic Journal of Management, 8(4), 416-437. http://dx.doi.org/10.1108/BJM-12-2012-0115

Ting Cheng. (2011). CPA Review of Domestic Human Resources Management. Era Trade, 17(3), 59-65.

Xiuping Hao. (2013). CPAs Human Resource Management Risk. Human Resource Management, 9(4), 44-49. 